\title{
Applications of the joint probability method for extreme sea level computations
}

\author{
D. T. PUGH \& J. M. VASSIE
}

\section{Mr T. D. Ruxton, Binnie \& Partners}

The Authors conclude that the joint probability method can be used to obtain stable values for forecasts of extreme sea levels from very short periods of accurately measured data. Even a single year can yield a useful result. The penalties are the effort needed to achieve the necessary accuracy of measurement and the extra computation.

45. In the British Isles this approach could find favour for expensive developments for which several methods of analysis would generally be used. However, 3-5 years' records would be needed. For many purposes the much less complicated method proposed by Lennon ${ }^{3}$ will be accepted as sufficiently accurate. The method relies on knowing the similarity measure, i.e.

\section{0 year high water level - mean high water springs spring range}

46. Graff ${ }^{7}$ proposes values for the similarity measure for much of the coastline of Great Britain. Using his value of 0.26 for Aberdeen and 0.16 for Newlyn, the 100 year high water levels comparable with those given by the Authors (relative to mean sea level) are $2.7(5) \mathrm{m}$ and $3.3 \mathrm{~m}$ respectively. Table 7 also makes the comparison with the values calculated by $\mathrm{Graff}^{7}$ using annual maxima.

47. The Authors produce arguments and evidence (\$\& 22-23) to suggest that surge activity is a stationary process. They also suggest that the apparently episodic nature of extreme tidal levels is due to the small sample of combined events. While this may be so, the work of Führböter ${ }^{18}$ would suggest that such short periods of data as 9 and 18 years are not sufficient to demonstrate the point conclusively. He suggests that climate change is responsible for differences of more than $0.8 \mathrm{~m}$ in estimates of the 100 year high water level from different 50 year periods of annual maxima at Cuxhaven. The climate changes needed to give rise to such changes have also been described by Painting ${ }^{19}$ and Lamb and Weiss. ${ }^{20}$ Without considerably more evidence from much longer records surely the Authors' arguments must be open to question.

48. If one is prepared to assume surge activity is a stationary process the joint probability method could be used to examine extreme values that lie outside the range of other values. Examples of such values are given by Wessex Water 
Authority. ${ }^{21}$ They are the high water levels at Avonmouth of $9 \cdot 2 \mathrm{~m}$ OD of 30 January, 1607 , and $9.0 \mathrm{~m}$ OD of 8 December, 1703, the day of the great storm written about by Daniel Defoe. The annual maxima method suggests extremely long return periods for these events that appear unrealistic. With the help of the Institute of Oceanographic Sciences, the Water Authority say that the higher tide of 1607 was the combination of a high spring tide (0-1 m lower than HAT) and a moderate surge of about $1.2 \mathrm{~m}$. This is a conceivable event and a probability could be found for it. Are the tidal observations in the area and the Authors' prediction techniques sufficiently accurate to allow a return period for this event to be calculated?

49. The Authors say $(\$ 22)$ that tidal probabilities may be adequately computed from an analysis of a year of data. In $\S 6$ they say that 18 years of hourly predictions were generated for this purpose. Davies ${ }^{22}$ shows that probabilities of extreme levels are larger in years when the nodal tide adds to tidal levels. Do the Authors accept this? Is this why in their own work they used a full set of values?

\section{Mr A. T. Walden, University of Southampton}

An important question that arises in the study of relationships between probabilities and return periods concerns the justification of the use of 1-dependence ( $\$ 17$ ). While agreeing that the hourly samples of sea level observations are not independent, I would not subscribe to their being 1-dependent. Hoeffding and Robbins ${ }^{23}$ define a sequence of random variables $\left\{x_{i}\right\}$ to be $m$-dependent if $|i-j|>m$ implies $x_{i}$ and $x_{j}$ are independent. Hence 1 -dependence means that $|i-j|>1$ implies $x_{i}$ and $x_{j}$ are independent (or, for practical purposes, have negligible correlation). Treating the hourly samples of sea level $\left\{x_{i}\right\}$ as a realization of a stationary stochastic process, the empirical autocorrelations may be computed; the correlogram for Portsmouth in 1965 (for lags up to 180) is given in Fig. 8 by way of example. Other British locations would give rise to similar plots. The (auto)correlation is cyclic in nature and is very high for certain $|i-j|>1$ (i.e. lags $>1$ ), and even 100-dependence would not be appropriate.

51. One case where 1-dependence would be a reasonable practical approxi-

Table 7. Hundred year high water levels relative to mean sea level*

\begin{tabular}{l|c|c|c|c|c|c}
\hline \multirow{2}{*}{ Method } & \multicolumn{3}{|c|}{ Aberdeen } & \multicolumn{3}{c}{ Newlyn } \\
\cline { 2 - 7 } & Mean & Maxima & Minimum & Mean & Maxima & Minimum \\
\hline $\begin{array}{l}\text { Joint } \\
\text { probability }\end{array}$ & $\begin{array}{c}2.91 \\
(9)\end{array}$ & $\begin{array}{c}2.99 \\
(1)\end{array}$ & $\begin{array}{c}2.75 \\
(1)\end{array}$ & $\begin{array}{c}3.41 \\
(18)\end{array}$ & $\begin{array}{c}3.51 \\
(1)\end{array}$ & $\begin{array}{c}3.17 \\
(1)\end{array}$ \\
\hline $\begin{array}{l}\text { Annual } \\
\text { maxima }\end{array}$ & $\begin{array}{c}2.8 \\
(67)\end{array}$ & $\begin{array}{c}3.0 \\
(15)\end{array}$ & $\begin{array}{c}2 \cdot 7(5) \\
(10 \text { and 20) }\end{array}$ & $\begin{array}{c}3.3 \\
(61)\end{array}$ & $\begin{array}{c}3.3 \\
(35)\end{array}$ & $\begin{array}{c}3.1 \\
(10)\end{array}$ \\
\hline $\begin{array}{l}\text { Similarity } \\
\text { measure }\end{array}$ & $2.7(5)$ & & & 3.3 & & \\
\hline
\end{tabular}

* Numbers in brackets are number of years' data used in computing the value. Maxima and minima for the annual maxima method are based on analysis of independent sequential sets of maxima. 


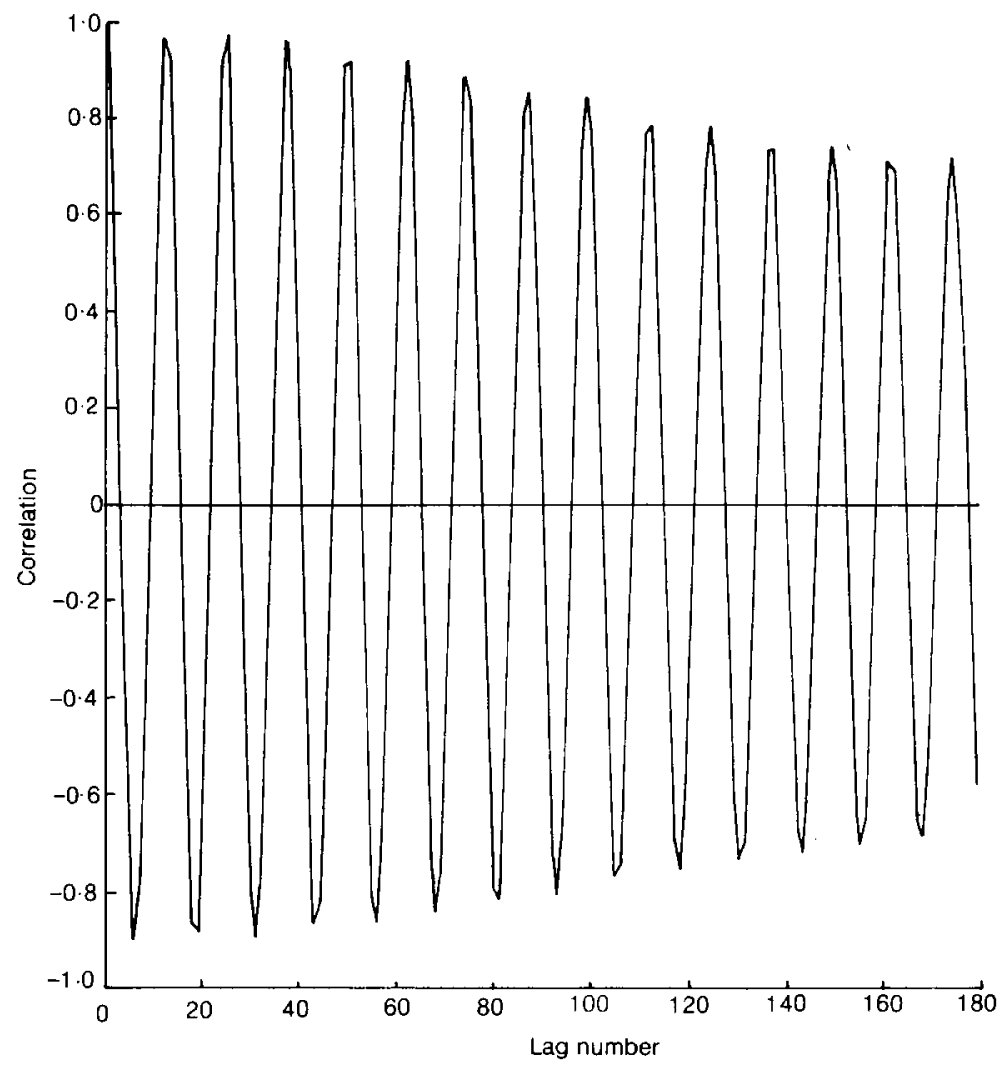

Fig. 8. Correlogram for Portsmouth hourly observed sea levels, 1965

mation involves a process which is well known. Consider a Markov process $x_{i}=\alpha x_{i-1}+\varepsilon_{i}$, where $\alpha$ is a constant $(|\alpha|<1)$ and $\left\{\varepsilon_{i}\right\}$ is a purely random process with mean zero and variance $\sigma_{\varepsilon}^{2}$. The autocorrelation at lag $k$ is $\alpha^{|k|}$ (see, for example, Chatfield ${ }^{24}$ ). Hence if $\alpha=0.1$ (say) it follows that for lags $\pm 1, \pm 2$, $\pm 3 \ldots$ the (auto)correlations are $0 \cdot 1,0.01,0.001 \ldots$, so that the correlation is negligible for lags with magnitude exceeding 1 , and 1-dependence is clearly appropriate.

Mr J. D. C. Osorio, Lewis \& Duvivier/Kampsax-Perhall Ltd

Correct determination of the probable typhoon surge level in Hong Kong is a matter of great economic importance as development on reclaimed land is proceeding at a rapid pace. Continuous water level data are available for one point since 1953 and for other places for shorter times. From 1953 to 1960 the gauge settled progressively but it is believed that this spurious secular trend has been identified and removed from the data. Typhoon surges are readily identifiable events and the separation of the meteorological and astronomical effects is not as 
difficult as it is in UK waters. In 1965 Peterson ${ }^{25}$ calculated the joint probabilities of the recombined data generally as described by the Authors. Later a numerical model was constructed and calibrated and this gives water levels for each hour for any chosen point in the colony's territorial waters, which can be treated as hourly events to increase the data available from the notable storms (about 30) for which data are available. There are thus now four types of analysis available

(a) extreme probability plot of annual maxima

(b) a log linear plot of all notable high water levels

(c) joint probability analysis

(d) analysis based on hourly output from the dynamic model.

The predictions obtained from methods $(b)$ and $(c)$ are similar; $(a)$ gives lower levels and $(d)$ gives higher levels.

53. Why do traditional analysts use annual maxima? The choice of either all notable events or a shorter arbitrary increment-say, weekly maxima-would avoid waste of data without involving the difficulties of the joint probability method.

54. The joint probability analysis makes the fundamental assumption that tide and surge do not interact. This cannot be true generally and it seems that it should be tested in any particular case.

\section{Dr Pugh and Dr Vassie}

Within the Institute of Oceanographic Sciences the similarity measure which $\mathrm{Mr}$ Ruxton discusses is sometimes used in making estimates of the probabilities of extreme levels. While results which agree roughly with those estimated by other techniques are usually obtained, there are examples where the assumptions of regional stability for the similarity measure are not satisfactory. This limitation is most apparent where tidal ranges are small and where there are extensive areas of shallow water; particular examples are Lowestoft (small range), Marsh Road Sluice in the Wash, Newport in the Bristol Channel, and Aberystwyth. ${ }^{7 * 26}$

56. We agree that estimates of the probabilities of extreme levels based on short periods of data are not ideal. Our technique makes optimum use of whatever data are available, and we urge that all such data are used when making estimates. The purpose of $\S 22$ was to determine the degree of confidence that could be placed in estimates based on very short lengths of data. Trends, for example in climate or due to siltations, are more readily identified by our treatment than by studies of annual maxima alone, and such trends may easily be incorporated in the estimating procedure. When estimating probabilities of extreme wave amplitudes, similar problems of insufficient data and apparent climatic trend occur, but useful and acceptable estimates are obtained from a single year of observations.

57. We had originally intended to include computations for the sites in the Bristol Channel for which the Wessex Water Authority have historical data and for which we had computed tide and surge levels. However, we were unable to find data from sites close enough to Kingston Seymour and Clevedon for generating surge statistics. It would be useful to make a systematic collection of such recorded extreme levels from around the coast, and to incorporate them into modern estimates.

* Reference 7 has now been published in Estuarine, Coastal and Shelf Science, 1981, 12, Apr., 389-449. 


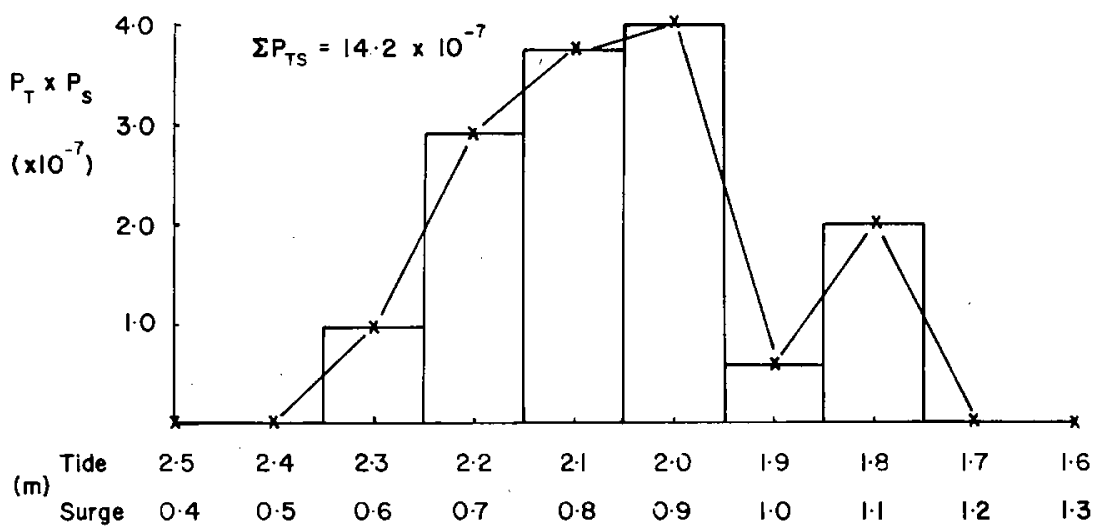

Fig. 9. Aberdeen 1 in 100 year probability

58. From a year of sea-level data it is possible to obtain good estimates of the harmonic tidal constituents. When computing the tidal probabilities we used 18 years of hourly predictions to allow for the nodal modulations (about $2 \%$ in amplitude in the case of the principal lunar semi-diurnal constituent $M_{2}$ ). These theoretical modulations are applied to the constituents obtained from analysis of the one year of data. An extreme total level is most likely to occur with a large tide and a large surge together, rather than with an extreme of either component. This is confirmed in Fig. 9 which shows the probabilities of tide-surge combinations which contribute to the total 1 in 100 year return period equivalent probability for Aberdeen. The most likely combinations are $2.2 \mathrm{~m}, 2.1 \mathrm{~m}$ or $2.0 \mathrm{~m}$ tides with $0.7 \mathrm{~m}, 0.8 \mathrm{~m}$ or $0.9 \mathrm{~m}$ surges superimposed.

59. By 1-dependence we refer to the property of a sequence of stochastic variables $\left\{X_{n}\right\}$ that the probability function depends solely on the probability function of the preceding term in the sequence, i.e.

$$
P\left(X_{r}=x_{r} \mid X_{r-1}=x_{r-1}\right) \quad r=0,1,2, \ldots
$$

This is the general definition of a lag-1 Markov chain and permits finite autocorrelations at non-zero lags. The equation $x_{i}=\alpha x_{i-1}+\varepsilon_{i}$ mentioned by $\mathrm{Mr}$ Walden is a special case where the autocorrelation function is predetermined by $\alpha$. In the general case the autocorrelation function at lags greater than 1 is not zero and may be periodic.

60. Although we cannot answer for traditional analysts, one argument for selecting the annual maxima is the seasonal cycle in both tidal and surge phenomena. A recent study ${ }^{27}$ of extreme waves has concerned the use of monthly maxima. Taking only total maxima, even over short periods, would not optimize the data usage as extremes of both tides and surges would be included only when they corresponded with large values of the other component. We have made a careful investigation of the extent of interaction (\$24-27) and considered one way of treating data where interaction occurs. For our purposes, only Southend statistics showed significant interaction, and we believe that extensive areas of shallow 
water are necessary before interaction becomes important. Nevertheless, it would be sensible to check in particular cases, using methods similar to ours.

61. In the penultimate line of $\S 11,-0.2 \mathrm{~m}$ should read $-0.4 \mathrm{~m}$.

\section{References}

18. FunRboter A. Frequencies and probabilities of extreme storm surges. Proceedings I6th coastal engineering conference, Hamburg, 1978. American Society of Civil Engineers, New York, 1979, 1, 949-964.

19. Painting D. J. A study of some aspects of the climate of the northern hemisphere in recent years. HMSO, London, 1976, Scientific paper 35.

20. LAMB W. H. and Weiss I. On recent changes of wind and wave regime of the North Sea and the outlook. Fachl. Mitt., 1979, No. 194, Mar.

21. WESSEX WATER AUTHORITY. Land drainage survey report under the Water Act 1973 Section 24(5). Somerset Local Land Drainage District, Wessex Water Authority, Bristol, 1979.

22. Davies J. R. Discussion on The 60 year sea level at Barnstaple as estimated using the convolution method, by K. J. George and D. J. Bates. Proc. Instn Civ. Engrs, Part 2, 1981, 71, Mar., 283-285.

23. HoEfFding $\mathbf{W}$. and RobBins $H$. The central limit theorem for dependent random variables. Duke Math. J., 1948, 15, 773-780.

24. Chatfield C. The analysis of time series: theory and practice. Chapman and Hall, Lonidon, 1975.

25. Peterson P. Storm surge statistics. Hong Kong Royal Observatory, 1975, Note 20.

26. Graff J. Private communication, 1981.

27. Cartier D. T. J. and Challenor P. G. Estimating return values of environmental parameters. Q.J.R. Met. Soc., 1981, 107, No. 451, 259-266. 